\title{
GENETICAL ANALYSIS OF CHROMOSOME SUBSTITUTION LINES OF BREAD WHEAT USING SECOND GENERATION HYBRIDS
}

\author{
J. W. SNAPE, C. N. LAW, C. F. YOUNG and A. J. WORLAND \\ Plant Breeding Institute, Maris Lane, Trumpington, Cambridge CB2 2LQ
}

Received 30.x.78

\section{Summary}

\begin{abstract}
An extension of the triparental 1 crossing procedure of Law (1966) and Aksel (1967) is described for the analysis of genetic variation between chromosome substitution lines of wheat. This extension involves the development of the complete set of second-generation hybrids. Examination of the means and variances of these generations enables not only the detection and estimation of additive and dominance effects but also the detection of withinchromosome segregation and between-chromosome interaction.

The analysis is used to elucidate the genetic control of ear emergence time in chromosome substitution lines of chromosomes $5 \mathrm{~A}$ and $5 \mathrm{D}$ from the variety Hope into the variety Chinese Spring. The results are in agreement with previous analyses but the greater precision now available indicates a more complex genetic situation than previously detected.
\end{abstract}

\section{INTRODUCTION}

Crossing procedures involving inter-varietal chromosome substitution lines of bread wheat, Triticum aestivum $(2 n=6 x=42)$ enable genetic analysis of quantitative variation determined by single chromosomes to be carried out (Law, 1966, 1968, 1972; Aksel, 1967; Snape, Law and Worland, 1975, 1977). One of these procedures, termed the triparental cross 1, estimates the genetical differences between two non-homologous substitution lines and their respective recipient chromosomes and also the interaction between the non-homologous pairs. This analysis involves growing first-generation hybrids and as such the effects estimated relate to the whole chromosome as the unit of segregation. However, it can be extended by the inclusion of certain second-generation hybrids (Aksel, 1967) to provide genetic analysis of within-chromosome epistasis and segregation for each chromosome pair. The present paper describes the extension of this genetic analysis to the complete set of second-generation hybrids of the triparental cross 1 procedure. This is an extension of Aksel's analysis which enables the detection of within-chromosome segregation by examination of second-degree as well as first-degree statistics and also the elucidation of the types of interaction between the non-homologous chromosomes. The use of this analysis is illustrated using data from crosses involving substitution lines of chromosomes $5 \mathrm{~A}$ and $5 \mathrm{D}$ from the variety Hope into the variety Chinese Spring.

\section{ANALysis of geNeration means}

The triparental cross 1 scheme involves crossing and selfing two single chromosome substitution lines $\left(S_{\mathfrak{i}}\right.$ and $\left.S_{j}\right)$ and their recipient variety $(R)$ in a diallel fashion to produce six first-generation hybrids, namely, 


$$
R, S_{i}, S_{j}, R \times S_{i}, R \times S_{j}, S_{i} \times S_{j} .
$$

If these generations are further crossed and selfed the complete set of 21 second-generation hybrid families is produced. These provide, however, only 20 genetically different generations since the crosses of $\mathrm{R} \times\left(S_{\mathrm{i}} \times \mathrm{S}_{\mathrm{j}}\right)$ and $\left(S_{1} \times R\right) \times\left(S_{j} \times R\right)$ produce the same set of genotypes.

The family expectation of each generation can be expressed in terms of its segregation for each homologous pair and these are shown in table 1. Here $P_{R}$ and $P_{S}$ refer to the parental recipient and substituted chromosomes respectively, and $B_{R}$ and $B_{S}$ the backcrosses of the $R \times S F_{1}$ hybrids to the recipient and substituted chromosomes, respectively.

TABLE 1

Family expectations of second-generation triparental 1 cross hybrids for each substituted chromosome

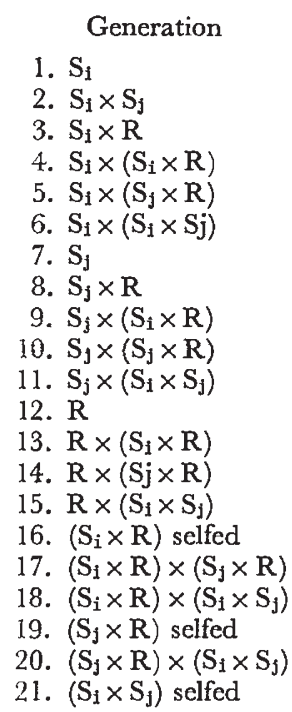

Chromosome i

Chromosome j

$\begin{array}{ll}\mathrm{P}_{\mathrm{s}} & \mathrm{P}_{\mathrm{R}} \\ \mathrm{F}_{1} & \mathrm{~F}_{1} \\ \mathrm{~F}_{1} & \mathrm{P}_{\mathrm{R}} \\ \mathrm{B}_{\mathrm{S}} & \mathrm{P}_{\mathrm{R}} \\ \mathrm{F}_{1} & \mathrm{~B}_{\mathrm{R}} \\ \mathrm{B}_{\mathrm{S}} & \mathrm{B}_{\mathrm{R}} \\ \mathrm{P}_{\mathrm{R}} & \mathrm{P}_{\mathrm{S}} \\ \mathrm{P}_{\mathrm{R}} & \mathrm{F}_{1} \\ \mathrm{~B}_{\mathrm{R}} & \mathrm{F}_{1} \\ \mathrm{P}_{\mathrm{R}} & \mathrm{B}_{\mathrm{S}} \\ \mathrm{B}_{\mathrm{R}} & \mathrm{B}_{\mathrm{S}} \\ \mathrm{P}_{\mathrm{R}} & \mathrm{P}_{\mathrm{R}} \\ \mathrm{B}_{\mathrm{R}} & \mathrm{P}_{\mathrm{R}} \\ \mathrm{P}_{\mathrm{R}} & \mathrm{B}_{\mathrm{R}} \\ \mathrm{B}_{\mathrm{R}} & \mathrm{B}_{\mathrm{R}} \\ \mathrm{F}_{2} & \mathrm{P}_{\mathrm{R}} \\ \mathrm{B}_{\mathrm{R}} & \mathrm{B}_{\mathrm{R}} \\ \mathrm{F}_{2} & \mathrm{~B}_{\mathrm{R}} \\ \mathrm{P}_{R} & \mathrm{~F}_{2} \\ \mathrm{~B}_{R} & \mathrm{~F}_{2} \\ \mathrm{~F}_{2} & \mathrm{~F}_{2}\end{array}$

Comparisons between the means of these generations provide scaling tests for the detection of the genetical effects for each substituted chromosome separately and for the interaction between them.

\section{(i) Detection of segregation within chromosomes}

Two sets of families for each substituted chromosome are segregating for that chromosome on a constant background. The first set, namely, $P_{R}, P_{S}, F_{1}, F_{2}, B_{R}$ and $B_{S}$ has a $P_{R}$ background for the other substitution line and the second set, $P_{R}, F_{1}, F_{2}, B_{R}$ and $B_{S}$ has a $B_{R}$ background for the other substitution line. These families are equivalent to the conventional $\mathrm{P}_{1}, \mathrm{P}_{2}, \mathrm{~F}_{1}, \mathrm{~F}_{2}, \mathrm{~B}_{1}$ and $\mathrm{B}_{2}$ families; the genetical expectations of the means of which are given by Mather and Jinks (1971) and table 2 shows these expectations with respect to a single gene and two or more genes in coupling phase with a recombination frequency p. Here the sign in front of the $\{d\}$ and $\{p j\}$ parameters will depend on whether the substituted chromosome carries increasing loci $(+)$ or decreasing loci $(-)$ with respect to the 
TABLE 2

Genetical expectations of family means for one gene and two or more genes for the substituted line for chromosome $i$ (genes in coupling)

Generation

\begin{tabular}{lllll}
\multicolumn{1}{c}{ Set 1} & \multicolumn{1}{c}{ Set 2} & & \multicolumn{1}{c}{1 gene } & 2 or more genes \\
$\mathrm{S}_{\mathrm{i}}$ & & - & $m \pm d$ & $m \pm\{d\}+\{i\}$ \\
$\mathrm{R}$ & $\mathrm{R} \times\left(\mathrm{S}_{\mathrm{j}} \times \mathrm{R}\right)$ & $m \pm d$ & $m \pm\{d\}+\{i\}$ \\
$\mathrm{S}_{\mathrm{i}} \times \mathrm{R}$ & $\mathrm{S}_{1} \times\left(\mathrm{S}_{\mathrm{j}} \times \mathrm{R}\right)$ & $m+h$ & $m+\{h\}+\{l\}$ \\
$\left(\mathrm{S}_{\mathrm{i}} \times \mathrm{R}\right)$ selfed & $\left(\mathrm{S}_{\mathrm{i}} \times \mathrm{R}\right) \times\left(\mathrm{S}_{\mathrm{i}} \times \mathrm{S}_{\mathrm{j}}\right)$ & $m+\frac{1}{2} h$ & $m+\frac{1}{2}\{h\}+\frac{1}{2}\{i\}-\{p i\}+\frac{1}{2}\{l\}-\{p l\}+\left\{p^{2} l\right\}$ \\
$\mathrm{S}_{\mathrm{i}} \times(\mathrm{Si} \times \mathrm{R})$ & $\mathrm{S}_{\mathrm{i}} \times\left(\mathrm{S}_{\mathrm{i}} \times \mathrm{S}_{\mathrm{j}}\right)$ & $m \pm \frac{1}{2} d+\frac{1}{2} h$ & $m \pm \frac{1}{2}\{d\}+\frac{1}{2}\{h\}+\frac{1}{2}\{i\}-\frac{1}{2}\{p i\} \pm \frac{1}{2}\{p j\}+\frac{1}{2}\{l\}-\frac{1}{2}\{p l\}$ \\
$\mathrm{R} \times\left(\mathrm{S}_{\mathrm{i}} \times \mathrm{R}\right)$ & $\mathrm{R} \times\left(\mathrm{S}_{1} \times \mathrm{S}_{\mathrm{j}}\right)$ & $m \pm \frac{1}{2} d+\frac{1}{2} h$ & $m \pm \frac{1}{2}\{d\}+\frac{1}{2}\{h\}+\frac{1}{2}\{i\}-\frac{1}{2}\{p i\} \pm \frac{1}{2}\{p j\}+\frac{1}{2}\{l\}-\frac{1}{2}\{p l\}$
\end{tabular}

TABLE 3

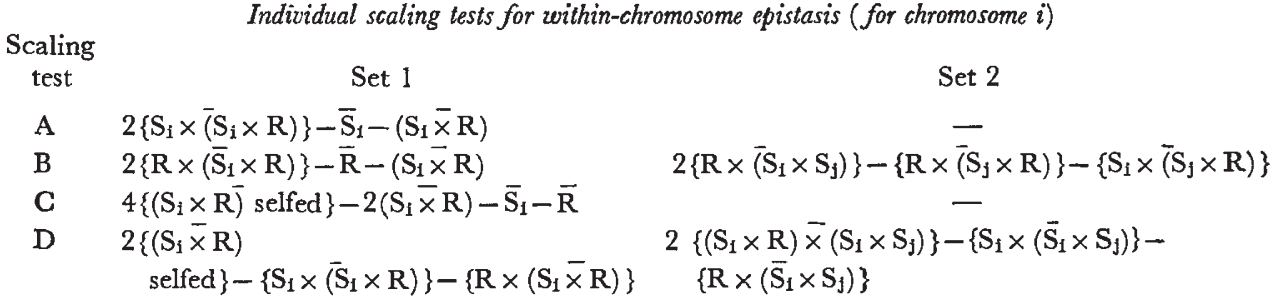

recipient chromosome. It can be seen from these expectations that within chromosome segregation if present will only be detected by scaling tests on generation means if the loci interact. Thus the generation means of these families cannot give unambiguous tests of within-chromosome segregation.

Individual scaling tests for within-chromosome epistasis are shown in table 3. These are equivalent to the $\mathrm{A}, \mathrm{B}, \mathrm{G}$ and $\mathrm{D}$ scaling tests given by Mather and Jinks (1971) for conventional generation means. Standard errors for these scaling tests can be obtained from the standard errors of the means of the generations in the usual manner.

A joint scaling test (Mather and Jinks, 1971) on each set of means can also be carried out by specifying a model of three parameters, $m,\{d\}$ and $\{h\}$ for each chromosome set. If epistasis is absent then this will provide least squares estimates of the balanced additive and within-chromosome interaction (dominance) effects of the substitution lines. Since the background is constant, these parameters will be completely correlated with epistatic effects between the chromosome and the background as with the triparental cross 1 estimates on the first-generation hybrids, and are thus not unambiguous estimates of the additive and dominance effects. However, tests of interaction with the background can be determined by carrying out a triparental cross 2 analysis for the chromosomes in question (Law, 1972).

\section{(ii) Between chromosome interaction}

The scaling test for non-homologous chromosome interaction on the first generation hybrids detects the summed contribution of the individual additive $\times$ additive ( $i$ effects), additive $\times$ within-chromosome interaction $(j$ effects) and within chromosome interaction $\times$ within chromosome interaction ( $l$ effects) (Law, 1972). As such this test is influenced by the type 
of interaction (whether duplicate or complementary) and by the association or dispersion of the increasing chromosomes, so that in many cases interaction will not be detected, even if present, because of the balancing effect of opposing interaction parameters. However, the inclusion of the segregating generations allows tests of the individual interaction parameters, irrespective of the type of interaction and chromosomal arrangement. Scaling tests to detect these effects are shown in table 4 . If significant effects are present then the sign of the estimates relative to the additive and within-chromosome interaction effects should also indicate the type of interaction present.

In the presence of significant within-chromosome epistasis these tests will not provide unambiguous tests of the non-homologous chromosome interaction since they will be confounded with the within-chromosome epistatic

\section{TABLE 4}

Tests of between chromosome interaction parameters

Interaction parameter

$\{i\}_{\mathrm{ij}}$ *

$\{j\}_{\text {ij }} \dagger$

$\{j\}_{j i} \dagger$

$\{l\}_{\mathrm{ij}}$

Scaling test

$$
\begin{aligned}
& \left.4\left\{\left(\mathrm{~S}_{1} \times \overline{\left.\mathrm{S}_{\mathrm{j}}\right)} \text { selfed }\right\}-2\left\{\mathrm{~S}_{\mathbf{i}} \times \overline{\left(\mathrm{S}_{\mathrm{i}}\right.} \times \mathrm{S}_{\mathrm{j}}\right)\right\}-2\left\{\mathrm{~S}_{\mathrm{j}} \times \overline{\left(\mathrm{S}_{\mathrm{i}}\right.} \times \mathrm{S}_{\mathrm{j}}\right)\right\}
\end{aligned}
$$

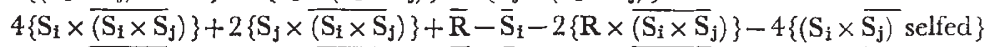

$$
\begin{aligned}
& 4\left\{\mathrm{~S}_{j} \times \overline{\left(\mathrm{S}_{\mathbf{i}} \times \mathrm{S}_{j}\right)}\right\}+2\left\{\mathrm{~S}_{\mathbf{i}} \times \overline{\left(\mathrm{S}_{\mathbf{i}} \times \mathrm{S}_{j}\right)}\right\}+\overline{\mathrm{R}}-\overline{\mathrm{S}}_{\mathbf{j}}-2\left\{\mathrm{R} \times \overline{\left.\left(\mathrm{S}_{\mathbf{1}} \times \mathrm{S}_{j}\right)\right\}-4\left\{\left(\mathrm{~S}_{\mathbf{i}} \times \overline{\mathrm{S}}_{\mathbf{j}}\right)\right.} \text { selfed }\right\} \\
& \left.\overline{\mathrm{S}}_{\mathbf{i}}+\overline{\mathrm{S}}_{\mathrm{j}}+2\left\{\mathrm{~S}_{\mathrm{i}} \times \mathrm{S}_{\mathrm{j}}\right\}+4\left\{\left(\mathrm{~S}_{\mathrm{i}} \times \overline{\left.\mathrm{S}_{\mathrm{j}}\right)} \text { selfed }\right\}-4\left\{\mathrm{~S}_{\mathrm{i}} \times \overline{\left(\mathrm{S}_{\mathrm{i}}\right.} \times \mathrm{S}_{\mathrm{j}}\right)\right\}-4\left\{\mathrm{~S}_{\mathrm{j}} \times \overline{\left(\mathrm{S}_{\mathrm{i}}\right.} \times \mathrm{S}_{\mathrm{j}}\right)\right\}
\end{aligned}
$$

* For the substituted chromosomes in dispersion this test estimates $-\{i\}_{i j}$.

$\dagger$ Tests estimate $-\{j\}_{\mathrm{ij}}$ and $-\{j\}_{\mathrm{fI}}$ if dispersion and substituted chromosome carrying decreasing alleles.

effects. However, if necessary, these effects can be adjusted for by estimating the relative contributions of these confounding interactions from scaling tests on the generations segregating for each substituted chromosome separately using the generations shown in table 2.

\section{(iii) Overall analysis}

The above scaling tests will detect the individual within-chromosome and between-chromosome effects for both substitution lines. However, all lines can be combined in a joint scaling test and a successive model fitting procedure carried out. In the absence of epistasis, both within- and betweenchromosomes, a model of only five parameters should explain the variation between the 21 generation means namely $m,\{d\}_{\mathrm{i}},\{d\}_{\mathrm{j}},\{h\}_{\mathrm{i}},\{h\}_{\mathrm{j}}$. Here $m$ is the mean of all homozygous lines that can be derived from this set of crosses and $\{d\}_{\mathrm{i}},\{d\}_{\mathrm{j}}$ the balanced additive effects of the $\mathrm{i}$ and $\mathrm{j}$ chromosomes and $\{h\}_{\mathrm{i}}$ and $\{h\}_{\mathrm{j}}$ the respective within-chromosome interaction (dominance) effects of the substituted chromosomes. This model allows 16 degrees of freedom to test the goodness of fit.

If this basic model fails, then the addition of parameters specifying epistasis is necessary. If the individual scaling tests detected between chromosome epistasis then this can be completely specified by the addition of the four parameters $\{i\}_{\mathrm{ij}},\{j\}_{\mathrm{ij}},\{j\}_{\mathrm{ji}}$ and $\{l\}_{\mathrm{ij}}$, leaving 12 degrees of freedom to test the goodness of fit. The expectations for each generation on this model are shown in table 5. If this model is inadequate then para- 
TABLE 5

Expectations of family means-chromosomes in association ( $R=\mathrm{aabb}, S_{i}=\mathrm{AAbb}, S_{i}=\mathrm{aaBB}$ )

Generation
1. $\mathrm{S}_{1}$
2. $\mathrm{S}_{1} \times \mathrm{S}_{\mathrm{j}}$
3. $\mathrm{S}_{\mathrm{i}} \times \mathrm{R}$
4. $\mathrm{S}_{1} \times\left(\mathrm{S}_{\mathrm{i}} \times \mathrm{R}\right)$
5. $\mathrm{S}_{1} \times\left(\mathrm{S}_{\mathrm{j}} \times \mathrm{R}\right)$
6. $\mathrm{S}_{\mathrm{i}} \times\left(\mathrm{S}_{1} \times \mathrm{S}_{\mathrm{j}}\right)$
7. $\mathrm{S}_{\mathrm{j}}$
8. $\mathrm{S}_{\mathrm{j}} \times \mathrm{R}$
9. $\mathrm{S}_{\mathrm{j}} \times\left(\mathrm{S}_{\mathrm{i}} \times \mathrm{R}\right)$
10. $\mathrm{S}_{\mathrm{j}} \times\left(\mathrm{S}_{\mathrm{j}} \times \mathrm{R}\right)$
11. $\mathrm{S}_{\mathrm{j}} \times\left(\mathrm{S}_{1} \times \mathrm{S}_{\mathrm{j}}\right)$
12. $\mathrm{R} \times\left(\mathrm{S}_{1} \times \mathrm{R}\right)$
13. $\mathrm{R} \times\left(\mathrm{S}_{1} \times \mathrm{R}\right)$
14. $\mathrm{R} \times\left(\mathrm{S}_{\mathrm{j}} \times \mathrm{R}\right)$
*15. $\mathrm{R} \times\left(\mathrm{S}_{1} \times \mathrm{S}_{\mathrm{j}}\right)$
16. $\left(\mathrm{S}_{\mathrm{i}} \times \mathrm{R}\right) \mathrm{selfed}$
*17. $\left(\mathrm{S}_{1} \times \mathrm{R}\right) \times\left(\mathrm{S}_{\mathrm{j}} \times \mathrm{R}\right)$
18. $\left(\mathrm{S}_{\mathrm{i}} \times \mathrm{R}\right) \times\left(\mathrm{S}_{\mathrm{i}} \times \mathrm{S}_{\mathrm{j}}\right)$
19. $\left(\mathrm{S}_{\mathrm{j}} \times \mathrm{R}\right)$ selfed
20. $\left(\mathrm{S}_{\mathrm{j}} \times \mathrm{R}\right) \times\left(\mathrm{S}_{\mathrm{i}} \times \mathrm{S}_{\mathrm{j}}\right)$
21. $\left(\mathrm{S}_{1} \times \mathrm{S}_{\mathrm{j}}\right)$ selfed

\begin{tabular}{|c|c|c|c|c|c|c|c|}
\hline $\mathrm{m}$ & $\mathrm{d}_{\mathrm{i}}$ & $d_{j}$ & $h_{1}$ & $h_{j}$ & $\mathbf{i}_{1 \mathbf{j}}$ & $j_{1 j}$ & $\mathrm{j}_{\mathrm{j} 1}$ \\
\hline 1 & 1 & -1 & 0 & 0 & -1 & 0 & 0 \\
\hline 1 & 0 & 0 & I & 1 & 0 & 0 & 0 \\
\hline 1 & 0 & -1 & I & 0 & 0 & 0 & -1 \\
\hline I & $\frac{1}{2}$ & -1 & $\frac{1}{2}$ & 0 & $-\frac{1}{2}$ & 0 & $-\frac{1}{2}$ \\
\hline 1 & 0 & $-\frac{1}{2}$ & I & $\frac{1}{2}$ & 0 & 0 & $-\frac{1}{2}$ \\
\hline I & $\frac{1}{2}$ & $-\frac{1}{2}$ & $\frac{1}{2}$ & $\frac{1}{2}$ & $-\frac{1}{4}$ & $\frac{1}{4}$ & $-\frac{1}{4}$ \\
\hline 1 & -1 & 1 & 0 & 0 & -1 & 0 & 0 \\
\hline . & -1 & 0 & 0 & I & 0 & -1 & 0 \\
\hline 1 & $-\frac{1}{2}$ & 0 & $\frac{1}{2}$ & I & 0 & $-\frac{1}{2}$ & 0 \\
\hline & $-\overline{1}$ & $\frac{1}{2}$ & 0 & $\frac{1}{2}$ & $-\frac{1}{2}$ & $-\frac{1}{2}$ & 0 \\
\hline 1 & $-\frac{1}{2}$ & $\frac{1}{2}$ & $\frac{1}{2}$ & $\frac{\pi}{2}$ & $-\frac{1}{4}$ & $-\frac{1}{4}$ & $\frac{1}{4}$ \\
\hline 1 & -1 & -1 & 0 & 0 & 1 & 0 & 0 \\
\hline I & $-\frac{1}{2}$ & -1 & $\frac{1}{2}$ & 0 & $\frac{1}{2}$ & 0 & $-\frac{1}{2}$ \\
\hline 1 & -1 & $-\frac{1}{2}$ & 0 & $\frac{1}{2}$ & $\frac{1}{2}$ & $-\frac{1}{2}$ & 0 \\
\hline 1 & $-\frac{1}{2}$ & $-\frac{1}{2}$ & $\frac{1}{2}$ & $\frac{1}{2}$ & $\frac{1}{4}$ & $-\frac{1}{4}$ & $-\frac{1}{4}$ \\
\hline 1 & 0 & -1 & $\frac{1}{2}$ & 0 & 0 & 0 & $-\frac{1}{2}$ \\
\hline 1 & $-\frac{1}{2}$ & $-\frac{1}{2}$ & $\frac{1}{2}$ & $\frac{1}{2}$ & $\frac{1}{4}$ & $-\frac{1}{4}$ & $-\frac{1}{4}$ \\
\hline 1 & 0 & $-\frac{1}{2}$ & $\frac{1}{2}$ & $\frac{1}{2}$ & 0 & 0 & $-\frac{1}{4}$ \\
\hline 1 & -1 & 0 & 0 & $\frac{1}{2}$ & 0 & $-\frac{1}{2}$ & 0 \\
\hline 1 & $-\frac{1}{2}$ & 0 & $\frac{1}{2}$ & $\frac{1}{2}$ & 0 & $-\frac{1}{4}$ & 0 \\
\hline 1 & 0 & 0 & $\frac{1}{2}$ & $\frac{1}{2}$ & 0 & 0 & 0 \\
\hline
\end{tabular}

* These generations have the same expectations and can be combined.

meters specifying within-chromosome epistasis become necessary. However, unless the loci within-chromosomes are segregating independently six parameters $\{i\},\{p \mathrm{i}\},\{p \mathrm{j}\},\{l\},\{p l\}$ and $\left\{p^{2} l\right\}$ are needed to specify the interactions within each of the substituted chromosomes (Jinks, 1978). Since for each chromosome only six different family types are available, the addition of these parameters will produce more parameters than there are equations to solve them, so that a fit cannot be obtained. However, simplification of the model assuming independently segregating genes within chromosomes can be introduced to try to obtain a fit. Nevertheless, if more than one gene on either chromosome is present then parameters will be estimates of net directional effects and these cannot be simply interpreted.

\section{ANALysis of generation VARIANGes}

The extension of the triparental cross 1 analysis to the second-generation hybrids enables second-degree statistics to be estimated from the generations which are segregating with respect to each chromosome. These families are of three types for each chromosome namely $F_{2}, B_{R}$ and $B_{S}$ families. Comparisons of the variances of these families with variances derived from non-segregating individuals can allow tests of within-chromosome segregation irrespective of the contribution of epistasis.

\section{(i) Scaling tests}

If the variation between the recipient and each substituted chromosome is mediated by a single gene then the variances between individuals within the $(\mathrm{S} \times \mathrm{R}) \mathrm{F}_{2}$ and backcross generations will be equal to the variance of 
the parental and $F_{1}$ individuals combined in their $F_{2}$ and backcross proportions. However, if two or more segregating loci are present then the variances may differ, and it can be shown that, for situations of loci predominantly in coupling phase that:

$$
\begin{array}{ll}
\mathrm{V}\{(\mathrm{S} \times \mathrm{R}) \text { selfed }\} & \equiv \mathrm{VF}_{2}<\mathrm{V}\left(\frac{1}{4} \mathrm{P}_{\mathrm{R}}+\frac{1}{2} \mathrm{~F}_{1}+\frac{1}{4} \mathrm{P}_{\mathrm{S}}\right) \\
\mathrm{V}\{(\mathrm{S} \times \mathrm{R}) \times \mathrm{R}\} & \equiv \mathrm{VB}_{\mathrm{R}}<\mathrm{V}\left(\frac{1}{2} \mathrm{P}_{\mathrm{R}}+\frac{1}{2} \mathrm{~F}_{1}\right) \\
\mathrm{V}\{(\mathrm{S} \times \mathrm{R}) \times \mathrm{S}\} & \equiv \mathrm{VB}_{\mathrm{S}}<\mathrm{V}\left(\frac{1}{2} \mathrm{P}_{\mathrm{S}}+\frac{1}{2} \mathrm{~F}_{1}\right)
\end{array}
$$

Alternatively if two loci in repulsion phase are present then the generation variances will be larger than the combined variances. With three or more linked genes, however, repulsion linkage is always accompanied by coupling linkage and in general the generation variance is not likely to be larger than the combined variance and segregation will not be detected. By growing the recipient, substitution lines and their $(S \times R) F_{1}$ hybrids in their $F_{2}$ and backcross proportions, together with the $\mathrm{F}_{2}$ and backcross generations for each chromosome, in a suitably designed randomised experiment, direct estimates of the relevant variances can be obtained and comparisons made using the F-ratio test. This test, however, is likely to be more sensitive to coupling linkage than to repulsion linkage.

One problem with this test is that the combined variances are based on exact ratios of parental and $F_{1}$ 's whereas the generation variances will be subject to the sampling error of genotype frequencies. However, this can be overcome by combining the parental and $F_{1}$ generations in their correct proportions and then taking a sub-sample at random.

The sensitivity of these scaling tests in detecting segregation will obviously depend on the magnitude of the gene effects and the recombination frequency between the linked loci. If linkage is loose and effects large relative to the environmental variation the number of loci segregating may also be discernible from discontinuities in the phenotypic distributions of individuals in the segregating generations; and by comparisons of these distributions with those of the parental and $F_{1}$ lines.

\section{(ii) Model fitting}

As with the generation means analysis the within-family variances of all families can be combined in a weighted least squares fitting procedure to test the adequacy of the alternative genetic models and also to provide estimates of the genetical components of variation for each substitution line. In the absence of epistasis and with independent segregation of loci within chromosomes a model of seven parameters is sufficient to explain the variation, namely $D_{i}, D_{j}$, the additive components of variance, $H_{i}, H_{j}$ the respective dominance components, $\mathrm{F}_{\mathrm{i}}$ and $\mathrm{F}_{\mathrm{j}}$, the covariance between $d$ and $h$ effects; and $\mathrm{E}$, the within-family environmental variance. The expectations for each generation on this model are shown in table 6. Here it will be observed that the six non-segregating generations and three other pairs have the same expectations so that the number of genetically different statistics is only 13. If this model adequately explains the observed variation, comparisons can be made between the variance components and the corresponding parameters obtained from the first-degree statistics. Thus if the variation is mediated by a single gene on each chromosome then $\{d\}^{2}=\mathrm{D}$ and $\{h\}^{2}=\mathrm{H}$. With two loci segregating then $\{d\}^{2}>\mathrm{D}$ when there is complete association of increasing loci, otherwise $\{d\}^{2}<\mathrm{D}$. Similarly 
TABLE 6

Expectation of within-family variances-chromosomes in association $\left(R=\mathrm{aabb}, S_{\mathbf{i}}=\mathrm{AAbb}\right.$, $\left.S_{\mathrm{j}}=\mathrm{aaBB}\right)$

Generation

1. $\mathrm{S}_{1}$

2. $\mathrm{S}_{\mathrm{i}} \times \mathrm{S}_{\mathrm{j}}$

3. $\mathrm{S}_{\mathrm{i}} \times \mathrm{R}$

4. $S_{i} \times\left(S_{i} \times R\right)$

5. $S_{i} \times\left(S_{j} \times R\right)$

6. $S_{i} \times\left(S_{i} \times S_{j}\right)$

7. $\mathrm{S}_{\mathrm{j}}$

8. $S_{j} \times R$

9. $S_{j} \times\left(S_{i} \times R\right)$

10. $S_{j} \times\left(S_{j} \times R\right)$

11. $S_{j} \times\left(S_{i} \times S_{j}\right)$

12. $\mathrm{R}$

13. $R \times\left(S_{i} \times R\right)$

14. $R \times\left(S_{j} \times R\right)$

15. $R \times\left(S_{i} \times S_{j}\right)$

16. $\left(\mathrm{S}_{i} \times \mathrm{R}\right)$ selfed

17. $\left(S_{i} \times R\right) \times\left(S_{j} \times R\right)$

18. $\left(S_{i} \times R\right) \times\left(S_{i} \times S_{j}\right)$

19. $\left(S_{j} \times R\right)$ selfed

20. $\left(S_{j} \times R\right) \times\left(S_{i} \times S_{j}\right)$

21. $\left(S_{i} \times S_{j}\right)$ selfed

$\begin{array}{ccc}\mathrm{D}_{\mathrm{i}} & \mathrm{D}_{\mathrm{j}} & \mathrm{H}_{\mathrm{i}} \\ 0 & 0 & 0 \\ 0 & 0 & 0 \\ 0 & 0 & 0 \\ \frac{1}{4} & 0 & \frac{1}{4} \\ 0 & \frac{1}{4} & 0 \\ \frac{1}{4} & \frac{1}{4} & \frac{1}{4} \\ 0 & 0 & 0 \\ 0 & 0 & 0 \\ \frac{1}{4} & 0 & \frac{1}{4} \\ 0 & \frac{1}{4} & 0 \\ \frac{1}{4} & \frac{1}{4} & \frac{1}{4} \\ 0 & 0 & 0 \\ \frac{1}{4} & 0 & \frac{1}{4} \\ 0 & \frac{1}{4} & 0 \\ \frac{1}{4} & \frac{1}{4} & \frac{1}{4} \\ \frac{1}{2} & 0 & \frac{1}{4} \\ \frac{1}{4} & \frac{1}{4} & \frac{1}{4} \\ \frac{1}{2} & \frac{1}{4} & \frac{1}{4} \\ 0 & \frac{1}{2} & 0 \\ \frac{1}{4} & \frac{1}{2} & \frac{1}{4} \\ \frac{1}{2} & \frac{1}{2} & \frac{1}{4}\end{array}$

$\begin{array}{crrr}\mathrm{H}_{\mathrm{j}} & \mathrm{F}_{\mathrm{i}} & \mathrm{F}_{\mathrm{j}} & \mathrm{E} \\ 0 & 0 & 0 & 1 \\ 0 & 0 & 0 & 1 \\ 0 & 0 & 0 & 1 \\ 0 & -\frac{1}{2} & 0 & 1 \\ \frac{1}{4} & 0 & +\frac{1}{2} & 1 \\ \frac{1}{4} & -\frac{1}{2} & +\frac{1}{2} & 1 \\ 0 & 0 & 0 & 1 \\ 0 & 0 & 0 & 1 \\ 0 & +\frac{1}{2} & 0 & 1 \\ \frac{1}{4} & 0 & -\frac{1}{2} & 1 \\ \frac{1}{4} & +\frac{1}{2} & -\frac{1}{2} & 1 \\ 0 & 0 & 0 & 1 \\ 0 & +\frac{1}{2} & 0 & 1 \\ \frac{1}{4} & 0 & +\frac{1}{2} & 1 \\ \frac{1}{4} & +\frac{1}{2} & +\frac{1}{2} & 1 \\ 0 & 0 & 0 & 1 \\ \frac{1}{4} & +\frac{1}{2} & +\frac{1}{2} & 1 \\ \frac{1}{4} & 0 & +\frac{1}{2} & 1 \\ \frac{1}{4} & 0 & 0 & 1 \\ \frac{1}{4} & +\frac{1}{2} & 0 & 1 \\ \frac{1}{4} & 0 & 0 & 1\end{array}$

$\{h\}^{2}>\mathrm{H}$ when dominance at both loci is reinforcing, otherwise $\{h\}^{2}<\mathrm{H}$ for situations of ambidirectional dominance.

If epistasis, either within or between chromosomes was detected using first-degree statistics then parameters specifying its contribution to the second-degree statistics become necessary. However, as with the means, their specification requires more statistics than are available and a fitting procedure will not be appropriate.

\section{EXAMple}

(i) Materials and methods

The example concerns an experiment carried out to investigate the genetics of ear emergence time using chromosome substitution lines of chromosomes 5A and 5D from the variety Hope into the variety Chinese Spring (CS). These lines were developed by Dr E. R. Sears at the University of Missouri, U.S.A., and had been used in previous investigations of ear emergence time (Law, 1972; Law, Worland and Giorgi, 1976).

The parental lines CS, CS(Hope 5A) and CS(Hope 5D) were first crossed to produce the first-generation hybrids. These were then crossed and selfed to produce the complete set of second-generation hybrids. These progenies were grown in a randomised field experiment from a spring sowing in 1975. Thirty-four plants from each family were sown with individual plant randomisation in each of two blocks. Ear-emergence time was scored from the date of the first plant to emerge.

\section{(ii) Results}

The analysis of variance with respect to variation in ear-emergence time for this experiment is shown in table 7. This analysis was carried out on

$$
42 / 2-1
$$


the family means and the within-family variance obtained by scaling down the sum of the within-family SS by the harmonic mean of the number of plants per family which, due to plant losses, were unequal and less than the number sown. There are highly significant differences between lines and blocks. However the blocks $\times$ lines interaction is only just significant and is not a major source of variation so that for further analysis the data has been pooled over blocks.

The means over blocks and the pooled within-family variance for each generation are shown in table 8. Here, for comparison with the earlier theory $\mathbb{R}=\mathrm{CS}, \mathrm{S}_{\mathrm{i}}=\mathrm{CS}($ Hope $5 \mathrm{~A})$ and $\mathrm{S}_{\mathbf{j}}=\mathrm{CS}$ (Hope 5D). Glearly both substitution lines are different from the recipient in ear-emergence time and this is confirmed by the triparental cross 1 analysis of the first-generation hybrids (table 9). Both additive and within-chromosome interaction (dominance) effects are significant for both chromosomes, although there is no evidence of between-chromosome epistasis. These results agree with those of Law (1972) in showing that the Hope 5A chromosome is signi-

TABLE 7

\begin{tabular}{lrrr}
\multicolumn{4}{c}{ Analysis of variance of ear emergence time } \\
$\quad$ Item & d.f. & M.S. & P \\
Lines & 20 & 33.340 & $<0.001$ \\
Blocks & 1 & $7 \cdot 118$ & $<0.001$ \\
Lines $\times$ blocks & 20 & 0.721 & 0.046 \\
Within families & 1054 & 0.451 &
\end{tabular}

TABLE 8

Mean ear emergence times and pooled within family variances

\begin{tabular}{|c|c|c|c|}
\hline Generation & Mean & No. plants & $\begin{array}{c}\text { family } \\
\text { variance }\end{array}$ \\
\hline 1. $\mathrm{CS}($ Hope $5 \mathrm{~A})$ & $6 \cdot 189$ & 57 & $7 \cdot 794$ \\
\hline 2. $\mathrm{CS}($ Hope $5 \mathrm{~A}) \times \mathrm{CS}($ Hope $5 \mathrm{D})$ & $9 \cdot 403$ & 53 & $5 \cdot 168$ \\
\hline 3. $\operatorname{CS}($ Hope $5 A) \times C S$ & $7 \cdot 156$ & 51 & 4.934 \\
\hline 4. $\mathrm{CS}($ Hope $5 \mathrm{~A}) \times\{\mathrm{CS}($ Hope $5 \mathrm{~A}) \times \mathrm{CS}\}$ & $7 \cdot 078$ & 56 & 4.954 \\
\hline 5. $\mathrm{CS}($ Hope $5 \mathrm{~A}) \times\{\mathrm{CS}($ Hope $5 \mathrm{D}) \times \mathrm{CS}\}$ & $7 \cdot 792$ & 50 & $3 \cdot 881$ \\
\hline 6. CS $($ Hope $5 \mathrm{~A}) \times\{\mathrm{CS}($ Hope $5 \mathrm{~A}) \times \mathrm{CS}($ Hope $5 \mathrm{D})\}$ & $6 \cdot 938$ & 60 & $5 \cdot 254$ \\
\hline 7. $\mathrm{CS}$ (Hope $5 \mathrm{D})$ & $22 \cdot 544$ & 49 & $6 \cdot 666$ \\
\hline 8. CS $($ Hope $5 \mathrm{D}) \times \mathrm{CS}$ & $14 \cdot 440$ & 52 & $3 \cdot 401$ \\
\hline 9. $\mathrm{CS}($ Hope $5 \mathrm{D}) \times\{\mathrm{CS}($ Hope $5 \mathrm{~A}) \times \mathrm{CS}\}$ & 13.098 & 55 & $16 \cdot 852$ \\
\hline 10. CS $($ Hope $5 \mathrm{D}) \times\{\mathrm{CS}($ Hope $5 \mathrm{D}) \times \mathrm{CS}\}$ & $18 \cdot 228$ & 54 & $27 \cdot 362$ \\
\hline 11. $\mathrm{CS}($ Hope $5 \mathrm{D}) \times\{\mathrm{CS}($ Hope $5 \mathrm{~A}) \times \mathrm{CS}($ Hope $5 \mathrm{D})\}$ & $14 \cdot 792$ & 48 & $23 \cdot 861$ \\
\hline 12. CS & 11.625 & 48 & $6 \cdot 750$ \\
\hline 13. $\mathrm{CS} \times\{\mathrm{CS}($ Hope $5 \mathrm{~A}) \times \mathrm{CS}\}$ & $9 \cdot 691$ & 50 & $9 \cdot 246$ \\
\hline 14. $\mathrm{CS} \times\{\mathrm{CS}($ Hope $5 \mathrm{D}) \times \mathrm{CS}\}$ & $13 \cdot 708$ & 47 & $12 \cdot 392$ \\
\hline 15. $\mathrm{CS} \times\{\mathrm{CS}($ Hope $5 \mathrm{~A}) \times \mathrm{CS}($ Hope $5 \mathrm{D})\}$ & $10 \cdot 128$ & 56 & $9 \cdot 030$ \\
\hline 16. $\{\mathrm{CS}($ Hope $5 \mathrm{~A}) \times \mathrm{CS}\}$ selfed & 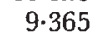 & 52 & $9 \cdot 650$ \\
\hline 17. $\{\mathrm{CS}($ Hope $5 \mathrm{~A}) \times \mathrm{CS}\} \times\{\mathrm{CS}($ Hope $5 \mathrm{D} \times \mathrm{CS}\}$ & 11.544 & 60 & $9 \cdot 463$ \\
\hline 18. $\{\mathrm{CS}($ Hope $5 \mathrm{~A}) \times \mathrm{CS}\} \times\{\mathrm{CS}($ Hope $5 \mathrm{~A}) \times \mathrm{CS}($ Hope & & & \\
\hline 5D)\} & $9 \cdot 358$ & 53 & 13.964 \\
\hline 19. $\{$ CS $($ Hope $5 D) \times C S\}$ selfed & $15 \cdot 840$ & 50 & $28 \cdot 142$ \\
\hline 20. $\{\mathrm{CS}($ Hope $5 \mathrm{D}) \times \mathrm{CS}\} \times\{\mathrm{CS}($ Hope $5 \mathrm{~A}) \times \mathrm{CS}($ Hope & & & \\
\hline 5D) $\}$ & $12 \cdot 144$ & 46 & $22 \cdot 643$ \\
\hline 21. $\{\mathrm{CS}($ Hope $5 \mathrm{~A}) \times \mathrm{CS}($ Hope $5 \mathrm{D})\}$ selfed & $12 \cdot 154$ & 51 & $29 \cdot 133$ \\
\hline
\end{tabular}

Pooled within family $7 \cdot 794$ $5 \cdot 168$ $4 \cdot 934$ $4 \cdot 954$ $3 \cdot 881$ $5 \cdot 254$ $6 \cdot 666$ $3 \cdot 401$ $27 \cdot 362$ $3 \cdot 861$ $6 \cdot 750$ $2 \cdot 392$ $9 \cdot 030$ 9. 650 .463 


\section{TABLE 9}

Estimated effects using first generation hybrids

\begin{tabular}{|c|c|c|}
\hline \multirow[b]{2}{*}{ Effect } & \multicolumn{2}{|c|}{ Substitution line } \\
\hline & CS(Hope 5A) & CS(Hope 5D) \\
\hline Additive & $-2 \cdot 718 * * *$ & $5.460 * * *$ \\
\hline $\begin{array}{l}\text { Within chromosome interaction } \\
\text { (dominance) } \\
\text { Between chromosome interaction }\end{array}$ & $-1 \cdot 751^{*}$ & $68^{-2 \cdot 644 * * *}$ \\
\hline
\end{tabular}

ficantly earlier than its CS homologue and the Hope 5D chromosome significantly later, with the effect of chromosome $5 \mathrm{D}$ being twice that of $5 \mathrm{~A}$.

These estimates are of course the balanced effects of these chromosomes and further analysis using the means of the second-generation hybrids can elucidate if within-chromosome epistasis and thus segregation is present.

The results of the scaling tests to detect within-chromosome epistasis for each chromosome are shown in table 10. One test for each chromosome is significant but only at the 5 per cent level. This suggests that epistasis may be present within both chromosomes, so that both may contain more than one locus affecting ear emergence. However, on combining the generations in a joint scaling test for each chromosome (table 11), only chromosome 5D exhibits epistasis.

The estimates of the genetic parameters on these scaling tests also enables the detection of between-chromosome epistasis. With respect to chromosome 5A, for example, the two estimates of additive effects obtained from the two sets of generations are significantly different from one another

\section{TABLE 10}

Scaling tests for within chromosome epistasis

$\begin{array}{lccc} & \text { Test } & \text { Chromosome 5A } & \text { Chromosome 5D } \\ & \text { A } & 0.811 & -0.528 \\ \text { Set 1 } & \text { B } & 0.601 & 1.351 \\ & \text { C } & 5.334 * & 0.311 \\ \text { Set 2 } & \text { D } & 1.961 & -0.256 \\ & \text { B } & -1.244 & -2.533 * \\ & \text { D } & 1.650 & -0.632 \\ & & * & \end{array}$

\section{TABLE 11}

Foint scaling tests for within chromosome epistasis

\begin{tabular}{|c|c|c|c|c|}
\hline \multirow[b]{2}{*}{ Parameter } & \multicolumn{2}{|c|}{ Chromosome 5A } & \multicolumn{2}{|c|}{ Chromosome 5D } \\
\hline & Set 1 & Set 2 & Set 1 & Set 2 \\
\hline $\begin{array}{r}\hat{m} \\
\{\hat{d}\} \\
\{\hat{h}\} \\
\chi^{2}\{\mathrm{df}\}\end{array}$ & $\begin{aligned} 9 \cdot 089 * * * \\
2 \cdot 699 * * * \\
-1 \cdot 388 * * \\
\{3\}=7 \cdot 027\end{aligned}$ & $\begin{aligned} & 9 \cdot 900^{* * *} \\
& 3 \cdot 567 * * * \\
- & 2 \cdot 186^{* *} \\
\{2\}= & 2 \cdot 851\end{aligned}$ & $\begin{aligned} 17 \cdot 141 * * * \\
5 \cdot 363^{* * *} \\
-2 \cdot 643^{* * *} \\
\{3\}=1 \cdot 604\end{aligned}$ & $\begin{array}{c}12.965^{* * *} \\
3.723^{* * *} \\
-0.581 \\
\{2\}=6.353^{*}\end{array}$ \\
\hline
\end{tabular}

Probabilities: ${ }^{*}=0 \cdot 05-0 \cdot 01 ; * *=0 \cdot 01-0 \cdot 001 ; * * *<0 \cdot 001$ 
as are the two estimates of the dominance effects. Since these estimates should be the same in the absence of correlated interaction effects with the $5 \mathrm{D}$ background this suggests that $5 \mathrm{~A}$ and $5 \mathrm{D}$ interact. This is supported by the difference in the estimates for chromosome $5 \mathrm{D}$, where this chromosome interacts with the $5 \mathrm{~A}$ background. Thus although the test of interaction on the first-generation hybrids was not significant, these results suggest that the chromosomes do, in fact, interact. This is confirmed by the scaling tests for the individual interaction parameters using the second-generation hybrids (table 12), where significant $l$ type interaction is detected. Since the interaction parameters have opposing signs and the two substituted chromosomes are in dispersion with respect to one another it is not surprising that the test on the first-generation hybrids was not significant since these are the conditions under which this test is insensitive (Law, 1972).

The above scaling tests indicate that both substituted chromosomes affect ear-emergence time. Dominance is present but incomplete and is towards earliness. Further, chromosome 5D exhibits within-chromosome epistasis suggesting that more than one locus is segregating on this chromosome. The two chromosomes also do not act independently in their effects on ear emergence but interact, with heterozygote $x$ heterozygote interactions being important.

The presence of these effects can be confirmed by the overall joint scaling test. Table 13 shows the estimates of the parameters obtained for the basic model of five parameters, and the model of nine parameters containing the between-chromosome interaction parameters. Neither model is adequate to explain the observed variation although the inclusion of betweenchromosome interaction parameters greatly improves the fit. This suggests that within-chromosome epistasis for one or both chromosomes is present since this is the only effect not allowed for. On the nine-parameter model three of the four interaction parameters are significant although only $l$ was

TABLE 12

Estimates of between chromosome interaction parameters

$\begin{array}{cc}\text { Parameter } & \text { Estimate } \\ \{i\}_{5 A .5 D} & -5 \cdot 156 \\ \{j\}_{5 A .5 D} & 6 \cdot 100 \\ \{j\}_{5 D} \text {.5A } & -6 \cdot 747 \\ \{l\}_{\text {5A.5D }} & 9.235 * \\ \text { * P }=0.05-0.01 .\end{array}$

TABLE 13

Foint scaling tests on the 21 generations

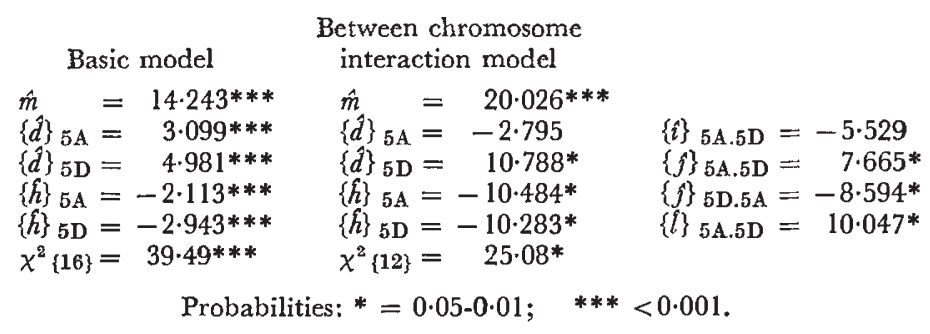


significant on the individual scaling tests. The estimates obtained are, however, very similar. The signs of the estimates compared to the additive and dominance effects suggest a complicated type of gene interaction situation with respect to the two non-homologous pairs. However, the $l$ interaction opposes the $h$ effects and the $j$ 's oppose their respective $d$ 's suggesting a predominantly duplicate type of interaction. This was found by Law (1972) and would be expected, of course, since the chromosomes are of the same homoeologous group and Law, Worland and Giorgi (1976) have shown homoeologous loci with large effects on ear-emergence time to be located on these chromosomes.

Tests of within-chromosome segregation can be obtained from comparisons of the generation variances of the segregating generations with variances of synthetic families of parental and $(R \times S) F_{1}$ individuals combined in their $\mathbf{F}_{2}$ and backcross proportions. Since in this experiment plants were individually randomised, these combined variances are simply obtained by allocating individuals at random from the parental and $F_{1}$ generations to the synthetic families in the correct proportions.

TABLE 14

Comparison of variances of segregating generations and parental and $F_{1}$ 's combined (df in brackets)

\begin{tabular}{|c|c|c|c|c|c|c|}
\hline & \multicolumn{3}{|c|}{$\mathrm{CS} \times \mathrm{CS}($ Hope $5 \mathrm{~A})$} & \multicolumn{3}{|c|}{$\mathrm{CS} \times \mathrm{CS}($ Hope $5 \mathrm{D})$} \\
\hline & $\begin{array}{c}\text { Generation } \\
\text { variance }\end{array}$ & $\begin{array}{c}\text { Combined } \\
\text { variance }\end{array}$ & $\begin{array}{c}\mathbf{P} \text { of } \\
\text { difference }\end{array}$ & $\begin{array}{c}\text { Generation } \\
\text { variance }\end{array}$ & $\begin{array}{l}\text { Combined } \\
\text { variance }\end{array}$ & $\begin{array}{c}\mathbf{P} \text { of } \\
\text { difference }\end{array}$ \\
\hline $\mathbf{F}_{2}$ & $9 \cdot 650(50)$ & $8 \cdot 924(98)$ & $0 \cdot 72$ & $28 \cdot 142(48)$ & $20 \cdot 787(102)$ & $0 \cdot 20$ \\
\hline Backcross to $\mathrm{S}$ & $4.954(54)$ & $5 \cdot 958(94)$ & 0.46 & $27 \cdot 362(52)$ & $24 \cdot 133(96)$ & 0.58 \\
\hline Backcross to $\mathrm{R}$ & $9 \cdot 246(48)$ & $10 \cdot 914(90)$ & 0.52 & $12 \cdot 392(45)$ & $7 \cdot 166(94)$ & 0.02 \\
\hline
\end{tabular}

The relevant variances are shown in table 14 together with the probabilities of difference. These were obtained from the variance ratios of the larger estimate over the smaller estimate and doubling the probability. With respect to chromosome $5 \mathrm{~A}$ no significant differences in the variances are apparent so that the variation on this chromosome would appear to be due to a single gene, which no doubt is the previously identified gene $\operatorname{Vrn} 1$ (Law et al., 1976). However for chromosome 5D there is a significant difference between the variances for the backcross generation to GS, suggesting, as did the generation means analysis, the presence of two or more segregating loci. Further, although the other two sets of variances are not significantly different, in all cases the combined variance is less than the corresponding generation variance. This suggests that the increasing alleles on $5 \mathrm{D}$ in this cross are predominantly in repulsion phase with respect to one another. One of these genes is undoubtedly $V r n 3$, identified by Law et al . (1976) as having a large effect, and the phenotypic distributions of the segregating generations show a discontinuity caused by segregation of this gene. However, these distributions do not show any other clear discontinuities, suggesting that the other gene(s) present are of much smaller effect.

Because of the presence of epistasis in this experiment it is not possible to estimate the individual components of variation. However, examination of the within-family variances (table 8) shows that significant genetic variation is exhibited by the segregating generations for both chromosomes. 
Also, these variances show, as with the first-degree statistics, that the effect of chromsome $5 \mathrm{D}$ on ear emergence is much greater than chromosome $5 \mathrm{~A}$ in this cross.

\section{Conclunsions}

The extension of the triparental cross $\mathrm{I}$ analysis to second-generation hybrids greatly increases the sensitivity of this crossing procedure in detecting and estimating the genetic effects of single chromosomes, particularly with respect to the detection of within-chromosome segregation and betweenchromosome interaction. Further the availability of segregating generations enables the estimation of second-degree statistics to be made whose analysis complements and reinforces the analysis of first-degree statistics.

The analysis of ear-emergence time using the substitution lines of chromosomes 5A and 5D from Hope into Chinese Spring using this method agrees very well with previous analyses using only first-generation hybrids. However, the greater precision possible highlights the limitations of the earlier analysis in detecting between-chromosome interaction and also shows that for chromosome $5 \mathrm{D}$ a gene(s) of small effect is segregating over and above the variation caused by segregation of $\mathrm{Vrn3}$.

Acknowledgements.-The authors are grateful to Professor J. L. Jinks and Dr A. J. Wright for their valuable comments on the manuscript.

\section{REFERENGES}

AKSEL, R. 1967. Quantitative genetic analysis of characters in wheat using cliromosome substitution lines (theoretical considerations). Genetics, 57, 195-211.

JINKs, J. L. 1978. Unambiguous test for linkage of genes displaying non-allelic interactions for a metrical trait. Heredity, 40, 171-173.

LAW, C. N. 1966. Biometrical analysis using chromosome substitutions within a species. In Chromosome Manipulations in Plant Genetics, eds. R. Riley and K. R. Lewis. Suppt. Heredity, 20, 59-85.

LAW, c. N. 1968. Genetic analysis using inter-varietal chromosome substitutions. Proc. 3rd Int. Wheat Genet. Symp., Canberra, 331-342.

LAW, C. N. 1972. The analysis of inter-varietal chromosome substitutions in wheat and their first generation hybrids. Heredity, 28, 169-179.

LAW, C. N., WORLAND, A. J., AND GIORGI, B. 1976. The genetic control of ear emergence time by chromosomes $5 \mathrm{~A}$ and $5 \mathrm{D}$ of wheat. Heredity, $36,49-58$.

MATHER, K., AND Jinks, J. L. 1971. Biometrical Genetics. Chapman and Hall Ltd., London. SNAPE, J. W., LAW, C. N., AND WORLAND, A. J. 1975. A method for the detection of epistasis in chromosome substitution lines of hexaploid wheat. Heredity, 34, 297-303.

SNAPE, J. W., LAW, C. N., AND WORLAND, A. J. 1977. Whole chromosome analysis of height in wheat. Heredity, 38, 25-36. 